\title{
Development of Green Logistics and Circular Economy Theory
}

\author{
Syed Abdul Rehman Khan ${ }^{1,2, *}$ and Yu Zhang ${ }^{3}$
}

\author{
${ }^{1}$ School of Management, Xuzhou University of Technology, Xuzhou, China \\ ${ }^{2}$ School of Economics and Management, Tsinghua University, Beijing, China \\ ${ }^{3}$ School of Economics and Management, Chang 'an University, Xi'an, China \\ *Corresponding author. Email: sarehman_cscp@yahoo.com
}

\begin{abstract}
Through the circular economy (CE) policy, China plans to achieve sustainable development ambition, aiming to minimize the extraction of raw materials and protect natural resources. Although the circular economy can be used as an essential policy tool to promote a more sustainable development trajectory, this theory can guide the green development of the logistics industry from the perspective of economic, resource and environmental symbiosis, which is manifested in three levels of enterprise, industry, and society. The green logistics evaluation system index is designed based on the regional logistics category, covering the micro level and macro level of the logistics industry. It corresponds to the three levels of circular economy practice. The theory of the analytic hierarchy process and fuzzy comprehensive evaluation is used to construct regional green logistics comprehensive development evaluation model to quantify and evaluate the development of regional green logistics.
\end{abstract}

Keywords: Circular economy theory, Green logistics management, Human-Environment interactions

\section{INTRODUCTION}

In recent years, theories of green logistics, reverse logistics, recycling logistics, and waste logistics have been continuously improved and developed. The green logistics evaluation system has become the standard for measuring the greening of enterprise logistics operations [1]. The circular economy is an economic model of economic, resource, and environmentally sustainable development. Circular economy (CE) is one of the main policy tools that has been used to reduce emissions Waste, protecting natural resources and biodiversity, and ecosystem (Fig. 1). The Chief Executive is focusing on the three Rs of emission Reduction, Reuse, and Recycling across different production processes to make them cleaner, greener and more cost-effective [2]. At present, the scientific literature on China's CE policy mainly focuses on increasing the effectiveness of productivity through stimulation of cleaner production at the enterprise level, promoting industrial symbiosis at the industrial cluster level, and establishing an ecological industry regional level network [3-5].

The concept of green logistics is based on the protection of socio-environmental sustainability [6-7]. By reforming logistics links such as transportation, storage, packaging, loading and unloading, and circulation processing, green logistics can achieve the goal of reducing environmental pollution and reducing resource consumption. The theory of circular economy can be used to guide the development of green logistics. This paper proposes a regional green logistics development evaluation system based on the theory of circular economy, aiming to provide a measure of green logistics development from the regional economic level.

\section{LITERATURE REVIEW}

There are many pieces of literature on domestic research on green logistics management, while there are few articles on green logistics evaluation indicators, mainly focusing on green logistics evaluation indicators and green logistics evaluation methods. The leading research on green logistics evaluation indicators is as follows. Cao et al. [8] and De Groot et al. [9] analyzed the evaluation institutions, evaluation systems, evaluation criteria, evaluation indicators, and evaluation methods around the structure and indicators of the eco-logistics evaluation system. Khan et al. [4] compares foreign social logistics evaluation indicators and concludes that countries formulate social logistics indicators from the perspectives of logistics functions, resources, industries, governments, consumers, etc., and clarify the idea of social logistics implicitly green logistics. Deng et al. [10] and Maron et al. [11] the four aspects of the external support level, development status, development trend and regional coordination of the logistics industry, the overall evaluation framework of the sustainable development of the logistics industry was established, and the specific evaluation index system was studied. Geng et al. [12] constructed a green logistics statistical indicator system from the transportation, distribution, warehousing, packaging, distribution processing, and reverse logistics of logistics. Liu et al. [13] 
divide the comprehensive benefits of green logistics into target factors such as economic benefits, social benefits, and ecological benefits. There is less research literature on green matter flow evaluation methods. The main research methods are the analytic hierarchy process, fuzzy comprehensive evaluation method, and neural network method.

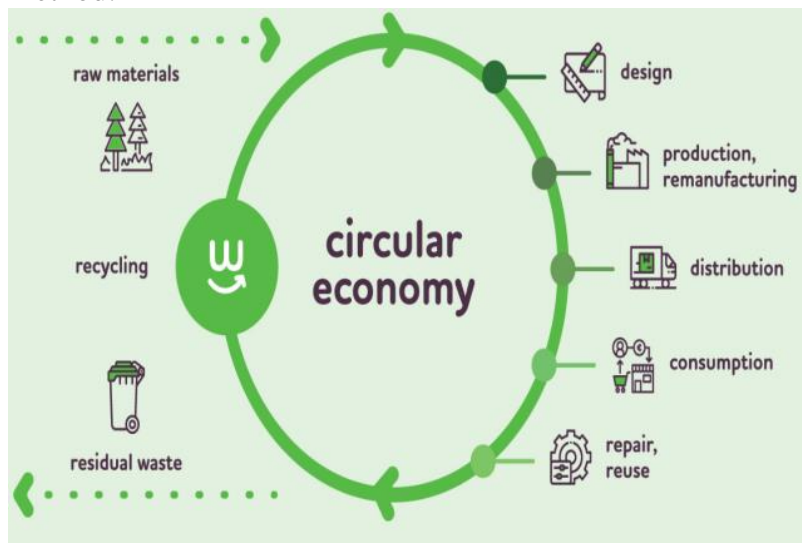

Figure 1. Circular economy

The existing literature has created a green logistics evaluation index and proposed a comprehensive evaluation method, which has effectively promoted the theoretical development and practice of green logistics, but it also has the following deficiencies. First, the green logistics evaluation index is based on a single level of logistics enterprises or logistics industry. It does not consider cooperation indicators between logistics enterprises and industries. Second, it focuses on the support indicators of logistics to the economy, and only discusses the resources (inside) of logistics enterprises themselves. Environmental issues, not considering the support indicators of the logistics enterprises (internal) on the economic benefits, ecological environment, and resource conservation of the service targets (external); third, the failure to establish coordination indicators for regional logistics and regional economic development.

It is necessary to actively promote the informationization, modernization, rationalization, and corporate social responsibility construction of logistics services, adhering to the most stringent land-saving system, focusing on energy conservation. Finally, the problem from industry development can be released or even be solved, like air, water and land pollution, high traffic accident, achieving economic and social sustainability. Coordinated development implies the green development of logistics enterprises and industries, and also emphasizes the coordination role of the logistics industry in economic and socially sustainable development.

This paper proposes a regional green logistics development evaluation system based on the theory of circular economy. The research object is regional green logistics, which involves two aspects. First, the green development of logistics itself includes not only the green management and operation of the logistics enterprise level but also the internal cooperation of the logistics industry and the improvement of the regional logistics infrastructure, which ultimately forms the green development of the regional logistics industry. Second, the promotion of the logistics industry. To support the green development of the regional economy, logistics has become an integral part of the regional green economy. This paper uses the theory of circular economy as the guiding ideology to construct the evaluation index and evaluation model for the coordinated development of green logistics and regional economy, environment, and resources from the three levels of an enterprise, region, and society.

It is of practical significance to study green logistics and its evaluation system from the perspective of regional economic sustainable development. First, re-recognize the positive and negative impacts of corporate logistics activities and effectively promote the development of green logistics. Logistics can reduce production costs and improve customer service levels for shippers. However, it also consumes energy and produces environmental pollution. Through the evaluation of the green logistics system, it can be better realized that logistics enterprises should minimize the consumption of resources and the impact on the environment while promoting economic development.

Second, it helps to promote the development of the green logistics industry. A single logistics company cannot meet all the logistics services of any cargo owner. It needs to form an internal collaboration between logistics companies to meet the supply chain logistics needs of the cargo owners while reducing the environmental impact and resource consumption of the entire supply chain.

Third, it is conducive to the development of the regional green logistics industry. Logistics nodes, distribution centres and other kinds of logistics nodes and transportation lines constitute a logistics infrastructure network, which is important for improving the regional investment environment, optimizing the industrial structure, and exerting urban agglomeration effects. The evaluation system can promote the docking of the logistics network and the regional industry, and the docking of the logistics park and the eco-industrial park. Green logistics is an integral part of the sustainable development of regional economies.

Fourth, it helps promote government policies on environmental protection. And the development of regulations. Logistics enterprises are a self-contained, independent operation, logistics. The disorderly development of the industry has caused massive waste of resource allocation. In green Environmental protection and resource-related policies and regulations can be strengthened in the logistics evaluation system development and implementation of indicators to strengthen the green development of the logistics industry Guide to the exhibition. 


\section{CIRCULAR ECONOMY AND REGIONAL GREEN LOGISTICS EVALUATION}

The sustainable development of the logistics industry refers to a balance between the ability of logistics to serve economic and social development and the ability to protect the ecological environment [14-15]. The sustainable development of the regional green logistics and logistics industry is the same. The construction of regional green logistics evaluation indicators should reflect the sustainable development of the logistics industry, and at the same time, attach importance to the relationship between the logistics industry and regional economy, environment, and resources.

Many previous papers have proposed green logistics evaluation indicators. The principle of following. Such as scientific principles, operability principles, comparability principles, dynamic principles, regional principles, qualitative and quantitative integration, systematic principles, principles of easy understanding. These principles are also the principles that should be followed in this evaluation system. According to the guiding ideology of circular economy theory, this paper constructs an index system to pursue the balanced development of the logistics industry and regional economy, environment, and resources. Therefore, the regional green logistics development and evaluation ideas of this paper mainly focus on the following three points.

There are three main characteristics of the logistics industry: service, infrastructure, and productivity. The serviceability of the logistics industry refers to the logistics activities such as transportation, warehousing, and distribution for the cargo owner. These activities need to provide the appropriate quality, quantity, time, place, object, price, and goods according to the owner's needs. If any of these 7 points cannot meet the customer's needs, it will not only generate logistics waste but also cause waste of the goods' value conversion. The logistics industry has infrastructure characteristics, which means that the logistics network facilities such as transportation lines and logistics parks are the infrastructure for national or regional economic development. The construction and operation of the logistics infrastructure all occupy resources. At the same time, if the repeated construction or operation is not efficient, the resources are wasted. The productivity of the logistics industry refers to the final implementation of the logistics industry to the level of corporate logistics activities, namely procurement logistics, production logistics, sales logistics and recycling logistics [16-17]. These logistics activities consume a lot of noise and exhaust gas while consuming energy. Regional green logistics is the target of this evaluation index, and we must effectively grasp these characteristics of the logistics industry.

Traditional green logistics practices and evaluation indicators, focus on the green activities of logistics companies, such as reducing packaging, collection and transportation, and joint distribution [18]. This is only part of green logistics. Because the greenness of a single logistics enterprise does not represent the degree of the greening of the entire industry, a single logistics enterprise cannot meet the full logistics needs of the owner. Green logistics is mainly manifested in two aspects of leanness and scale. A single logistics company may be lean, while scale requires collaboration among logistics companies.

In view of the current situation of China's logistics market, on the one hand, logistics enterprises have vicious competition, which hinders the benign development of the logistics industry; on the other hand, affected by the interests of administrative division, logistics centers and logistics parks all show the status or trend of redundant construction, lacking the overall layout of the logistics industry and the concept of global optimization; in addition, the logistics industry lacks policy support for logistics standardization and green development. It is also an obstacle to the development of green logistics. Therefore, when evaluating green logistics, it should be positioned as regional green logistics. Regional green logistics includes the lean operation of logistics enterprises, cooperation in the logistics industry, and the formulation of relevant policies and regulations for the logistics industry.

\section{RELATIONSHIP BETWEEN CIRCULAR ECONOMY AND GREEN LOGISTICS}

The green logistics evaluation system detects the internal greening of the logistics system, and also detects the interaction between the logistics system and the external economy, environment, and resources of the system. In the regional economy, logistics services are targeted at production and distribution enterprises, and logistics is a derivative service. The procurement, sales, and other activities of the production and distribution enterprises are derived from logistics, warehousing, transportation, distribution, packaging, and other services. These logistics services consume resources and affect the environment. If these services are not functioning properly, the goods will probably be destroyed, and the problems of energy shortage and environmental pollution will further deteriorate.

The practice of circular economy has three levels: small enterprise cycle, industry cycle, and social cycle. These levels are closely related to green logistics, so the regional green logistics evaluation system should reflect the correlation between logistics and circular economy [19]. Green procurement, green production, and green sales at the enterprise level require activities such as green logistics transportation and warehousing; circular economy industrial belts, industrial parks, and the "middle cycle" for comprehensive utilization between upstream and downstream enterprises require logistics parks and supply chain logistics support; the social cycle of sound legislation and resource sharing needs to improve the construction of logistics network infrastructure and accelerate the standardization of logistics and the construction of green regulations [20-22]. 


\section{GREEN LOGISTICS EVALUATION BASED ON CIRCULAR ECONOMY THEORY}

The evaluation activity is a goal-driven activity. The evaluation is carried out on the premise that there is a certain target or target system, and the evaluation index is subordinate to a certain target system. The goal of the evaluation system proposed in this paper is to improve the sustainable development level of the logistics industry and improve the green function of the logistics industry to serve the regional economy. To this end, the overall goal of regional green logistics development must be described, as shown in Fig. 2.

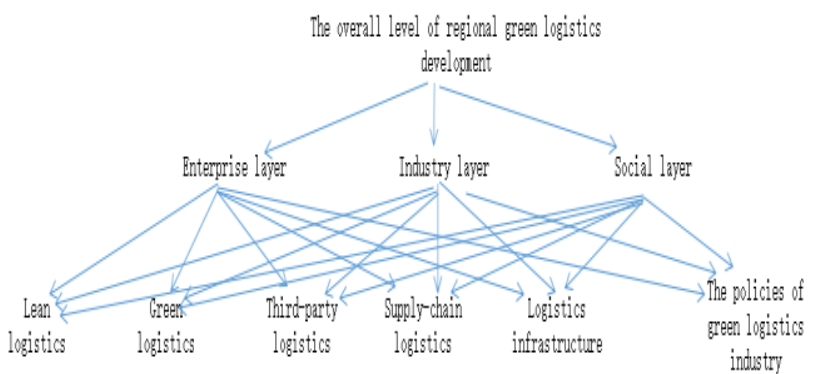

Figure 2. Regional Green Logistics Evaluation Index System

According to the principle of the Analytic Hierarchy Process (AHP), this paper systematically analyzes the overall level of regional green logistics development. First, layer the problem. By dividing the various factors in the problem into an orderly level of interconnection, and making it organized. According to the subjective judgment structure of a certain objective reality (mainly a pairwise comparison), the expert opinions and the objective judgment results of the analysts are directly effectively combined, and the importance of comparing the elements of the same level is quantitatively described. Then, mathematical methods are used to calculate the weights that reflect the relative importance order of the elements of each level, and the relative weights of all elements are calculated and sorted by the total ordering between all levels. Therefore, the target layer of the regional green logistics evaluation index system proposed in this paper is to judge the overall development level of regional green logistics. The standard consists of logistics enterprise-level, industry level, and social level. The enterprise-level of the program layer mainly includes three indicators: lean logistics, green logistics, and third-party logistics. The industry level is mainly measured by one indicator of supply chain logistics. The social level mainly consists of two indicators: logistics infrastructure and green logistics industry policy.

The development of regional green logistics needs to be carried out at the enterprise, industry, and social levels. It is necessary to achieve the green development of the logistics industry and the support of logistics for the production and circulation enterprises and the green development of the regional economy. The evaluation indicators mainly include lean logistics, green logistics, and third-party logistics outsourcing at the enterprise level. Lean logistics reflects the control of the internal logistics control and the accuracy of the production plan, reflecting that the logistics service fully meets the actual needs of the owner of the goods; the green management of logistics represents the green level of the logistics operation and management of logistics enterprises and enterprises; third-party logistics Outsourcing represents the degree of socialized optimization of logistics resources. Industry-level supply chain logistics management represents the integration and intensification of logistics operations among member companies in the supply chain. Social layer

The development of regional green logistics needs to be carried out at the enterprise, industry, and social levels. It is necessary to achieve the green development of the logistics industry and the support of logistics for the production and circulation enterprises and the green development of the regional economy. The evaluation indicators mainly include lean logistics, green logistics, and third-party logistics outsourcing at the enterprise level. Lean logistics reflects the control of the internal logistics control and the accuracy of the production plan, reflecting that the logistics service fully meets the actual needs of the owner of the goods; the green management of logistics represents the green level of the logistics operation and management of logistics enterprises and enterprises; third-party logistics outsourcing represents the degree of socialized optimization of logistics resources. Industry-level supply chain logistics management represents the integration and intensification of logistics operations among member companies in the supply chain. The degree of perfection of the logistics network at the social level represents the role of the logistics industry in supporting the infrastructure of the region; the green logistics industry policy helps to promote the improvement of the environmental, economic policy system by government departments. The indicator system proposed to improve the green level of regional logistics should have predictable functions for future development trends, which not only facilitates the relevant departments to grasp the development status but also predicts and controls the future more accurately and improves the efficiency of supervision.

\section{GREEN LOGISTICS DEVELOPMENT BASED ON FUZZY COMPREHENSIVE EVALUATION}

Considering that the indicators involved in the comprehensive benefit evaluation of green logistics are non-quantitative and cannot be directly compared by the general method, this paper combines the AHP method and the fuzzy comprehensive evaluation method to evaluate. The AHP method is used to determine the weight value between the relevant indicators at all levels, and then the 
fuzzy comprehensive evaluation method is used to comprehensively and correctly evaluate the regional green logistics development level. The basic evaluation steps are summarized as follows:

(1) Establish a set of factors (indicators) and a set of reviews for the evaluation model;

(2) Determine the weight value set of each group's related factors by AHP method;

(3) Establish a single indicator evaluation matrix;

(4) According to the fuzzy comprehensive evaluation method, the comprehensive evaluation results are obtained.

\section{ANALYTICAL MODEL}

According to the evaluation analytic model of Fig. 1, since the three criteria layers of green logistics development are affected by all indicators of the program layer, the regional green logistics evaluation index system shows the correlation between the program level indicators and the criterion level indicators. Therefore, this paper directly uses all indicators of the indicator layer to evaluate the comprehensive development level of regional green logistics, namely $\mathrm{U}=\{\mathrm{u} 1, \mathrm{u} 2, \mathrm{u} 3, \mathrm{u} 4, \mathrm{u} 5, \mathrm{u} 6\}=\{$ Lean logistics, green logistics, third-party logistics, supply chain logistics, logistics infrastructure, green logistics industry policy\}.

The comment set is a collection of various evaluation results that the evaluator may make to the evaluation object, the size of which may be determined by the actual situation and the size of the calculation amount. According to the current status of China's green logistics development, we have established a collection of reviews: $V=\{v 1, v 2, v 3$, $\mathrm{v} 4, \mathrm{v} 5\}=\{$ very good, good, average, poor, very poor $\}$, corresponding points The value set $\mathrm{F}=(100,80,60,40$, 20).

Using the combination of AHP and expert survey methods, experts are invited to form an evaluation team to evaluate them according to the different roles and relative importance of each indicator in the evaluation index system. See Table 1 . In order to reflect the pertinence and comprehensiveness of expert evaluation, a total of 12 personnel from logistics enterprises, production and circulation enterprises, university teachers, and government of the logistics industry were selected to form an expert evaluation team. In the case of pairwise comparison, the expert group compares any two elements at the same level of the hierarchical structure, usually assigning values to the importance of each index on a scale of 1 to 9 .

Table 1 Relative importance comparison table for ui-uj

\begin{tabular}{|c|c|c|c|c|c|c|}
\hline & $\mathbf{u 1}$ & $\mathbf{u 2}$ & $\mathbf{u 3}$ & $\mathbf{u 4}$ & $\mathbf{u 5}$ & $\mathbf{u 6}$ \\
\hline $\mathbf{u 1}$ & 1 & 2 & 3 & 2 & 5 & 9 \\
\hline $\mathbf{u 2}$ & $1 / 2$ & 1 & 2 & 1 & 3 & 1 \\
\hline $\mathbf{u 3}$ & $1 / 3$ & $1 / 2$ & 1 & 1 & 4 & 2 \\
\hline $\mathbf{u 4}$ & $1 / 2$ & 1 & 1 & 1 & 2 & 2 \\
\hline $\mathbf{u 5}$ & $1 / 5$ & $1 / 3$ & $1 / 4$ & $1 / 2$ & 1 & 1 \\
\hline $\mathbf{u 6}$ & $1 / 9$ & 1 & $1 / 2$ & $1 / 2$ & 1 & 1 \\
\hline
\end{tabular}

Normalize the matrix and obtain the eigenvectors $\mathrm{W}=$ $(0.3861,0.1725,0.1471,0.1510,0.0622,0.0810) . \quad \lambda=6.43$.

The stochastic consistency ratio is $\mathrm{G}=0.0625<0.1$, so it can be considered that lean logistics, green logistics, third-party logistics, supply chain logistics, logistics infrastructure, green logistics industry policy and other factors can reasonably evaluate the comprehensive development level of regional green logistics. The weights are $\mathrm{W}=(0.3861$, $0.1725,0.1471,0.1510,0.0622,0.0810) \mathrm{T}$.

Based on the development status of a regional logistics industry, the degree of the greening of the development of the local logistics industry will be evaluated. The economy of the region is dominated by private enterprises, forming an industrial cluster with regional characteristics, and the overall development level of the logistics industry is relatively low. By designing questionnaires, it will be distributed to business owners, government departments, college teachers and students, and ordinary consumers. From the six indicators of the guidelines, the status of green development of the local logistics industry will be evaluated and data will be obtained.

Table 2 Local Green Logistics Development Comprehensive Evaluation Statistics

\begin{tabular}{|c|c|c|c|c|c|c|}
\hline Index & Weight & Very good & Good & General & Bad & Worse \\
\hline $\mathbf{u 1}$ & 0.3861 & 0.5000 & 0.2000 & 0.2000 & 0.1000 & 0.0000 \\
\hline $\mathbf{u 2}$ & 0.1725 & 0.3000 & 0.3000 & 0.2000 & 0.2000 & 0.0000 \\
\hline $\mathbf{u 3}$ & 0.1471 & 0.3000 & 0.4000 & 0.2000 & 0.1000 & 0.0000 \\
\hline $\mathbf{u 4}$ & 0.1510 & 0.1000 & 0.2000 & 0.4000 & 0.2000 & 0.1000 \\
\hline $\mathbf{u 5}$ & 0.0622 & 0.3000 & 0.4000 & 0.2000 & 0.1000 & 0.0000 \\
\hline $\mathbf{u 6}$ & 0.0810 & 0.1000 & 0.1000 & 0.3000 & 0.4000 & 0.1000 \\
\hline
\end{tabular}

$\mathbf{R}=\left[\begin{array}{lllll}0.5000 & 0.2000 & 0.2000 & 0.1000 & 0.0000 \\ 0.3000 & 0.3000 & 0.2000 & 0.2000 & 0.0000 \\ 0.3000 & 0.4000 & 0.2000 & 0.1000 & 0.0000 \\ 0.1000 & 0.3000 & 0.4000 & 0.2000 & 0.1000 \\ 0.3000 & 0.4000 & 0.2000 & 0.1000 & 0.0000 \\ 0.1000 & 0.1000 & 0.3000 & 0.4000 & 0.1000\end{array}\right]$


Fuzzy comprehensive evaluation results: $\mathrm{B}=\mathrm{W} . \mathrm{R}=(0.3308,0.2510,0.2383,0.1567,0.0232)$.

Finally, the evaluation value of the green development level of the local logistics industry is obtained. $\mathrm{P}=\mathrm{B} * \mathrm{VT}=(0.3308,0.2510,0.2383,0.1567,0.0232) *(100,8$ $0,60,40,20) \mathrm{T}=74.19$

After a series of calculations, it is concluded that the comprehensive evaluation value of the development level of green logistics in the local area is 74.19, which is between 60 and 80 , that is, the comment is between "general" and "better." This shows that the overall effect of the implementation of the green logistics level is not bad, the overall greenness is higher than the general level, which is also consistent with the actual situation in the local area. Local private enterprises strictly control logistics costs, adopt logistics services that can only meet the current needs of regional survival, and have a lean logistics level. At the same time, due to the industrial cluster effect, the industrial chain is perfect and supply chain logistics partners coordinate their practices well. These two factors make local logistics industry greener. Of course, in order to improve the greening level of the logistics industry, the region can also start with accelerating the development of third-party logistics, improving logistics infrastructure, and green-colour logistics industry policies.

\section{CONCLUSION}

The evaluation of regional green logistics development based on the circular economy can be carried out from the enterprise, industry, and social level, including six factors: lean logistics, green logistics, third-party logistics, supply chain logistics, logistics infrastructure, and green logistics industry policy. These factors are related to the three levels of the regional circular economy. Therefore, the analytic hierarchy process is used to determine the weight of singlelevel indicators. The fuzzy evaluation matrix is used to evaluate the development of green logistics in specific regions. The quantitative analysis of the fuzzy evaluation model for the green logistics comprehensive development level will help all society to have a comprehensive understanding of green logistics, and thus effectively promote the development of regional green logistics.

\section{ACKNOWLEDGMENT}

This work is supported by the China Postdoctoral Science Foundation (No. 2019M660700), the Beijing Key Laboratory of Megaregions Sustainable Development Modelling, Capital University of Economics and Business (No. MCR2019QN09).

\section{REFERENCES}

[1] Khan, S.A.R., and Dong, Q. (2017). Impact of green supply chain management practices on firms' performance: an empirical study from the perspective of
Pakistan. Environmental Science and Pollution Research, 24(20), pp.16829-16844.

[2] Pan, X., Xu, L., Yang, Z., Yu, B., 2017. Payments for ecosystem services in China: policy, practice, and progress. J. Clean. Prod. 158, pp.200-208.

[3] Ban, N.C., Mills, M., Tam, J., Hicks, C.C., Klain, S., Stoeckl, N., et al., 2013. A social-ecological approach to conservation planning: embedding social considerations. Front. Ecol. Environ. 11, pp.194-202.

[4] Khan, S.A.R., Dong, Q., Zhang, Y., Khan, S.S. (2017). The impact of green supply chain on enterprise performance: In the perspective of China. Journal of Advanced Manufacturing Systems, 16(3), pp.263-273.

[5] Bracking, S., 2012. How do investors value environmental harm/care? Private equity funds, development finance institutions and the partial financialization of nature-based industries. Dev. Change 43, pp. 271-293.

[6] Cuperus, R., Canters, K.J., Udo de Haes, H.A., Friedman, D.S., 1999. Guidelines for ecological compensation associated with highways. Biol. Conserv. 90, pp.41-51.

[7] Khan, S.A.R., and Zhang, Y. (2019) Strategic Supply Chain Management, Springer International Publishing, Switzerland AG, ISBN 978-3-030-15058-7, DOI: 10.1007/978-3-030-15058-7.

[8] Cao, X., Kleit, A., Liu, C., 2016. Why invest in wind energy? Career incentives and Chinese renewable energy politics. Energy Policy 99, pp.120-131.

[9] De Groot, R.S., Wilson, M.A., Boumans, R.M., 2002. A typology for the classification, description and valuation of ecosystem functions, goods and services. Ecol. Econ. 41, pp. 393-408.

[10] Deng, J., Sun, P., Zhao, F., Han, X., Yang, G., Feng, Y., 2016. Analysis of the ecological conservation behavior of farmers in payment for ecosystem service programs in eco-environmentally fragile areas using social psychology models. Sci. Total Environ. 550, pp.382-390.

[11] Maron, M., Gordon, A., Mackey, B.G. Possingham, H.P., Watson, J.E., 2015. Conservation: Stop misuse of biodiversity offsets. Nature 523, pp.401403.

[12] Geng, Y., Fu, J., Sarkis, J., Xue, B., 2012. Towards a national circular economy indicator system in China: 
an evaluation and critical analysis. J. Clean. Prod. 23, pp.216-224.

[13] Liu, D., Zhu, L., 2014. Assessing China' s legislation on compensation for marine ecological damage: a case study of the Bohai oil spill. Mar. Policy 50, pp.18-26.

[14] Geng, Y., Sarkis, J., Ulgiati, S., Zhang, P., 2013. Measuring China's circular economy. Science 339, pp.1526-1527.

[15] Liu, H., Luo, Y.-B., Heinen, J., Bhat, M., Liu, Z.-J., 2014. Eat your orchid and have it too: a potentially new conservation formula for Chinese epiphytic medicinal orchids. Biodivers. conserve. 23, pp.1215-1228.

[16] Khan, S.A.R., Zhang, Y., Anees, M., Golpîra, H., Lahmar, A., Dong, Q. (2018). Green supply chain management, economic growth and environment: A GMM based evidence. Journal of Cleaner Production, 185(6), pp.588-599.

[17] Zhao, G., Liu, J., Kuang, W., Ouyang, Z., Xie, Z., 2015. Disturbance impacts of land use change on biodiversity conservation priority areas across China: 1990e2010. J. Geogr. Sci. 25, pp. 515-529.

[18] Pornprasit, P., Rurkkhum, S., 2017. Performance evaluation of community-based ecotourism: a case study in Satun province, Thailand. J. Ecotourism pp.118.
[19] Quigley, J.T., Harper, D.J., 2006. Effectiveness of fish habitat compensation in Canada in achieving No net loss. Environ. Manag. 37, pp.351-366.

[20] Khan, S.A.R., Zaman, K., and Zhang. (2016). The relationship between energy-resource depletion, climate change, health resources and the environmental Kuznets curve: Evidence from the panel of selected developed countries. Renewable and Sustainable Energy Reviews, 62(9), pp.468-477.

[21] Mandle, L., Douglass, J., Lozano, J.S., Sharp, R.P., Vogl, A.L., Denu, D., et al., 2016. OPAL: an open-source software tool for integrating biodiversity and ecosystem services into impact assessment and mitigation decisions. Environ. Model. Softw. 84, pp. 121-133.

[22] Mandle, L., Tallis, H., Sotomayor, L., Vogl, A.L., 2015. Who loses? Tracking ecosystem service redistribution from road development and mitigation in the Peruvian Amazon. Front. Ecol. Environ. 13, pp.309315. 